Article

\title{
An Analysis of the Implementation of Business Process Re-engineering in Public Services
}

\author{
Vishakha Wijeratne Elapatha and Shahzadah Nayyar Jehan * \\ Department of Community Service and Science, Tohoku University of Community Service \& Science, \\ Babacho 997-0035, Japan; g619002@gs.koeki-u.ac.jp \\ * Correspondence: jehan@koeki-u.ac.jp
}

Received: 2 September 2020; Accepted: 13 October 2020; Published: 14 October 2020

\begin{abstract}
Sri Lankan public service apparatus has a long colonial heritage, and all of that has not been in line with the requirements of a 21st century public service expectations. However, the increasing societal pressure for the delivery of more modern public services has forced it to undergo a major overhaul of its business process. In this paper, we assess the impact of the recent efforts at business process reengineering (BPR) in public service. We estimate the overall as well as relative efficiency of public service delivery across various ministries and departments of the Sri Lankan government. A broad-based Likert scale field survey on a five-point scale was carried out and performance data were collected. We applied a non-parametric data envelopment analysis (DEA) to estimate the overall and relative efficiency of the public service delivery across 29 departments and ministries (D\&Ms) and the departments of the government of Sri Lanka. Our results show that, save for a few, most D\&Ms have a potential for improving the performance. The performance enhancement is desirable both from an input as well as output perspectives. Moreover, our results indicate significant scale inefficiencies associated with the performance of ministries and departments that are engaged in public service delivery (PSD) in the country. The authors have also indicated towards critical success factors for a wider deployment of the study's findings in the conclusion.
\end{abstract}

Keywords: BPR; DEA; public service delivery; open innovation; Sri Lanka

\section{Introduction}

Sri Lanka's colonial heritage has a significant bearing upon the design as well and functioning of its public service apparatus. Despite being an ex-British colony like many other countries in the region, Sri Lanka's society and government structure is a special case unlike many of its neighboring countries. It will be of little use to see the country's historical and contemporary developments as a complimentary case of its neighboring nations. Meyers stated that there is more to be found by recognizing specificity of Sri Lanka than by regarding it as microcosm of India [1]. The service sector is considered an engine of growth for a country, and in a country like Sri Lanka the efficiency of public sector becomes immensely important, as it is the largest employer as well as deliverer of public services in the country. Hsieh conducted an exhaustive study on the role of services sector in the growth of East Asian economies and have asserted a strong relationship between the two [2]. With this background, the authors have made as effort to assess the impact of BPR in PSD in the country. While authors have attempted to put the case of BPR and PSD in a broader perspective, this is nonetheless a case with evidence and analysis related to original field data collected from public sector in Sri Lanka. While the data are unique, the model used and the findings are applicable to many other countries seeking improvement of PSD through BPR with expectations of improved efficiency of the public sector administration. 
Sri Lanka Administrative Services (SLAS — established 1972) is the successor to Ceylon Administrative Services (CAS-established 1963). CAS was, in turn, the successor to the much older Ceylon Civil Services (CCS-established 1833). While the purpose of CCS was to help British colonial power to govern over its colony, SLAS has significantly different demands and expectations from its Sri Lankan clients. While, SLAS is one major public service provider in Sri Lanka, its functions are supplemented, and sometimes even duplicated, by layers of other offices, across several D\&Ms. It certainly has been a great challenge for SLAS, along with other D\&Ms, to deliver modern public services in modern times with a design and functionality inherited from CCS. As a result of mounting expectations and demands of more modern, independent and highly educated populace, SLAS and many other D\&Ms of Sri Lanka underwent a major BPR regime during the last decade. BPR regime, in this context, meant (i) structural reforms, (ii) regulatory overhaul, and (iii) better performance control mechanisms. These three measures were put in place as mainstay of the BPR regime in order to ensure an efficient delivery of public services. While BPR was put into place, no effort has since been made to assess the propriety as well the outcome of the regime. In this paper we analyze the post-BPR-implementation state of affairs and measure the efficiency of the service across 29 D\&Ms of Sri Lankan government through which most public services are delivered to the populace.

Hammer et al. defined BPR as "fundamental rethinking and radical redesign of business processes to achieve dramatic improvements in critical, contemporary measures of performance" [3]. Moreover, according to Ezigbo, "BPR involves rethinking of the current theories of business. Remarkable improvements are made by breaking away from following the old methods and adopting the newer ones" [4]. Further BPR regime implementation has several aspects of open innovation as a continuous outside-in innovation element is ingrained in it; such is the purpose of this study, also, to allow the inside-outside-inside (IOI) feedback to the regime implementers. Gassmann et al. define open innovation as a bidirectional information process that leads to the process improvement, thus making open innovation a necessary corollary to BPR [5]. It must be noted that BPR is a continuous process instead of a one-time event; thus, it is imperative that a continuous IOI feedback process be carried on, thus allowing innovation be incorporated into the process.

This way of defining BPR takes account of two key areas important to our case, i.e., fundamental rethinking and radical redesign. As we mentioned earlier, the colonial heritage of the public service apparatus in Sri Lanka has historically been a major impediment in the way of developing a more modern service. Two critical areas that stand out as prime targets for a BPR regime are: first, fundamental rethinking of the philosophy; second, a complete redesign of the structure of the business process in order to provide public service in an efficient manner. It may be noted that BPR did not start in one go in Sri Lanka; rather, it took off incrementally over many years. Only by 2010 did it take a recognizable shape in the form of strategic, policy, and action initiatives. These measures in turn resulted in creation as well elimination of several D\&Ms across Sri Lanka. Re-engineering Government Program (Re-Gov) started with a blueprint issued in 2004 and sketched a detailed BPR process of public service with the program named 'Program D' with 24 (D1-D24) initiatives in various areas of governance targeted in the Sri Lanka. These measures were revealed in the eGovernment Strategy document prepared by Sri Lanka's Information and Communication Technology Agency (ICTA) in 2013 [6]. Now, as almost ten years have passed since various BPR measure were implemented across the public service delivery apparatus, it seems pertinent to evaluate the outcome of the regime by comparing various inputs into this regime in the form of rules, structure redesign, and performance controls. In the next section, we lay down the details of the data used and the methodology applied to estimate the outcome of the BPR.

\section{Literature}

As we noted in the introduction to this paper, Sri Lankan public services have origins in a philosophy that stood diametrically opposed to the modern concepts of public service. The public service management needed to undergo a thorough process of reform and restructuring. As there were 
not many internal examples to follow in order to reinvent the service apparatus to be in tune with modern age requirements, the only approach left to avail was a IOI concept for management innovation, reform and restructure. However, before we move, it seems important that we put our research in perspective by taking a quick round-up of the contemporary and empirical studies conducted on this topic to-date.

Several studies have touched upon the topic of public service reforms in Sri Lanka, but no efforts have yet been made to assess the impact of the third and the most recent wave of reforms in the form of BPR regime put into effect. Some studies, however, have attempted to assess the impact of the first wave or the second wave. This makes our study one of its nature, and the originality of data and the broader scope it carries makes it stand out when compared to any other study on the topic. Park et al. have conducted an extensive study on several developing economies in Asia and have found a strong linkage between PSD reform and economics growth; though their study is not particularly related to the case of Sri Lanka [7]. McCourt performed a cursory study of the three waves, and his findings were mostly related to employment reforms in Sri Lanka [8]. In the context of PSD in Sri Lanka, Deshani et al. noted the problem of the lack of innovation in Sri Lankan public services [9]. His findings indicated lack of a conceptual model with a core strategic leadership, as well as nonchalance towards a culture of achievement. As compared to the 3 rd wave, the 1 st and the 2 nd waves have been mostly economy-related reforms. Ghatari et al. studied the effectiveness of public service delivery in the Galle district of Sri Lanka only, and that too from the perspective of public entrepreneurship [10]. Ozcelik noted that if BPR is not properly performed, resulting integration can disrupt operations, impede productivity, hurt employee morale, and stifle growth [11]. The same has been emphasized by Hesson et al., that careful planning and analysis are essential for a smooth, uninterrupted transition to the new business processes [12]. James et al. carried out a BPR case study and found important linkages between BPR and public sector performance [13]. That is, however, is a limited study about BPR in a single town of UAE; but have listed quite a few interesting research articles to substantiate the utility of BPR for PSD. Chesbrough conducted an in-depth case study of a BPR project at the Housing and Development Board of Singapore to explore and identify the unique characteristics of BPR in public organizations [14]. Though the findings in [14] have limited scope, we would still like to acknowledge the educational and research value of the study in the field of BPR and its relation to public services.

After repeated halfhearted attempts at reforms through the 1960s and 1970s, a completely new approach towards governance was introduced in 2010 under the concept of ReGovernance 2020 (ReGov). The approach adopted in this outline document called for out of the box solutions and called for opening up almost all areas of public service for innovative approach towards business process. Hence, a BPR regime with IOI based open-innovation as its core was launched to overhaul and reform the public service mechanisms of Sri Lanka. This led to an open-innovation policy of redesigning the whole business model of the PSD in the country. It is important to implement BPR with due diligence, as otherwise the consequences can be disastrous for the organizational structure as well as for the related economy. In early 2000, the introduction of the concept of open innovation within BPR regime was a relatively new concept at the time. While explaining the concept of open innovation, Fernando stated that "open innovation combines internal and external ideas into architectures and systems whose requirements are defined by a business model". It was in this very context, that ReGov laid down an out-of-box reform process and kickstarted a great mesh IOI reform of the public service systems in Sri Lanka [15]. Here, we see a shadow of Wijesinghe's findings that stated that managerial innovations result in alterations in existing working patterns, systems, procedures, and styles, resulting in efficiency and effectiveness in the delivery of public services [16]. In short, open innovation serves as one of the core axioms of this reform wave; however, for the sake of focus and explanative ease, the paper mostly focuses on IOI based BPR regime in the Sri Lankan public services. Thanassoulis et al. stated that Sri Lankan public administration structure has undergone at least three distinct public reform waves [17]. The first wave, as explained in the report of the Administrative Reforms Committee 
(ARC), laid down detailed/linked proposals with a major focus on civil service size. However, the first wave was only partially implemented as most reform measures were hampered by political instability. As noted earlier, Deshani et al. asserts that the second wave came with a focus upon structural reform of the management units, but the target areas were not clear and thus resulted in greater mess, and an enlarged public sector with little performance improvement [9]. On the other hand, the third and the most recent wave has undertaken a major strategic shift in the philosophy and the structure of the public service administration.

BPR is composed mainly of (i) structural reforms, (ii) regulatory overhaul, and (iii) better performance control mechanisms as the mainstay of the regime in order to ensure an efficient PSD. While BPR regime was put into place, no effort has since been made to assess the propriety as well the outcome of the regime. In this paper, we analyze the post-BPR-implementation state of affairs and measure the efficiency of the service across 29 D\&Ms. In the next sections of the paper, we explain our data sources, the methodology applied to analyze the situation, and, finally, discuss the outcomes of our research and analysis.

\section{Data and Methodology}

\subsection{Data}

Data were collected through a questionnaire-based field survey conducted across 29 D\&Ms of the Sri Lankan government. The survey was conducted during February and March of 2020. In total, 290 respondents returned the completed questionnaire. The questionnaire was designed on a 5-point Likert type scale with 5 meaning strongly agreed, 4 agreed, 3 neutral, 2 disagreed and 1 for strongly disagreed (Table 1). Graduate students from Tohoku University of Community Service and Science, Japan, belonging to Sri Lanka visited, distributed the questionnaires, and collected the responses over a period of two months. Input questions were categorized into three focus areas of the regime, i.e., (i) Structure, (ii) Rules, and (iii) Control, and compared with the set of questions related to outcomes (Table 1). The questions were deliberately planned per se to verify the relationship of inputs with the outcomes of the BPR regime for PSD.

Table 1. Survey Questionnaire.

\begin{tabular}{cccccc}
\hline \multirow{2}{*}{ Questions } & \multicolumn{5}{c}{ Response } \\
\cline { 2 - 5 } & Strongly Agree & Agree & Neutral & Disagree & Strongly Disagree \\
\hline $\begin{array}{c}\text { Input Questions } \\
(1,2,3 \ldots 20)\end{array}$ & 5 & 4 & 3 & 2 & 1 \\
$\quad$ Structure & 5 & 4 & 3 & 2 & 1 \\
$\quad \begin{array}{c}\text { Rules } \\
\text { Control }\end{array}$ & 5 & 4 & 3 & 2 & 1 \\
Outcome Questions & 5 & 4 & 3 & 2 & 1 \\
$(1,2,3 \ldots 20)$ & & Total responses 290
\end{tabular}

Table 2 lists the D\&Ms from where the survey data were collected. Inputs and outcomes related responses of 10 employees from each of 29 D\&Ms were tabulated. The data thus collected were recorded into separate excel sheet and tabulated for further treatment and analysis. In the next stage, the data from the completed questionnaire collected from each D\&M were averaged, and the average response to each was used for processing and analysis through DEA software. The questions were designed as such to confirm the input into BPR and the output of the BPR regime through the functional structure of the public service delivery system. Furthermore, the questionnaire design allowed us to categorize the inputs into three major categories, i.e., structure, rules, and controls related to the service provision system across 29 departments and ministries (Table 2). While some departments come under 
relevant ministerial jurisdiction, many departments function as independent entities; hence, they have been considered as separate DMUs. The authors have denoted columns with numbers, e.g., column 1 contains names of departments and ministries surveyed and column 2 identifies each of them with a certain DMU number (Table 2). The columns $3 \mathrm{~b}$ to 6 show original input/output data averages from the questionnaire distributed and collected (Table 2).

Table 2. Input and Output Data.

\begin{tabular}{|c|c|c|c|c|c|}
\hline \multirow[b]{2}{*}{ Organization (Col. 1) } & \multirow[b]{2}{*}{$\begin{array}{c}\text { Decision } \\
\text { Making Unit } \\
\text { No. (Col. 2) }\end{array}$} & \multicolumn{4}{|c|}{ Input/Output Data } \\
\hline & & $\begin{array}{l}\text { Output } \\
\text { (Col. 3) }\end{array}$ & $\begin{array}{c}\text { Input } 1 \\
\text { Structure } \\
\text { (Col. 4) }\end{array}$ & $\begin{array}{c}\text { Input } 2 \\
\text { Rules } \\
\text { (Col. 5) }\end{array}$ & $\begin{array}{l}\text { Input } 3 \\
\text { Control } \\
\text { (Col. 6) }\end{array}$ \\
\hline Department of Pensions & DMU1 & 3.68 & 4.00 & 3.49 & 3.74 \\
\hline Department of Registrar General & DMU2 & 3.62 & 3.55 & 3.46 & 3.87 \\
\hline Ministry of Public Administration & DMU3 & 3.78 & 3.70 & 3.79 & 3.81 \\
\hline Ministry of Local Government & DMU4 & 3.72 & 3.70 & 3.68 & 3.77 \\
\hline Department of Revenue License & DMU5 & 3.61 & 3.60 & 3.51 & 3.73 \\
\hline Department of Railways & DMU6 & 3.77 & 3.70 & 3.79 & 3.79 \\
\hline Department of Wildlife Conservation & DMU7 & 4.04 & 3.98 & 4.08 & 4.01 \\
\hline Department of Examinations & DMU8 & 3.52 & 3.55 & 3.43 & 3.60 \\
\hline Ministry of Higher Education & DMU9 & 3.91 & 3.90 & 3.78 & 4.09 \\
\hline Ministry of Urban Development & DMU10 & 3.76 & 3.63 & 3.58 & 4.07 \\
\hline Department of Irrigation & DMU11 & 3.40 & 3.38 & 3.32 & 3.51 \\
\hline Department of Excise & DMU12 & 3.66 & 3.68 & 3.48 & 3.87 \\
\hline Department Immigration Emigration & DMU13 & 3.76 & 3.83 & 3.77 & 3.71 \\
\hline Department Import \& Export & DMU14 & 3.59 & 3.73 & 3.56 & 3.56 \\
\hline Department of Co. Registration & DMU15 & 3.42 & 3.55 & 3.33 & 3.44 \\
\hline Department Inland Revenue & DMU16 & 3.70 & 3.80 & 3.52 & 3.86 \\
\hline Department of Persons Registration & DMU17 & 3.75 & 3.88 & 3.52 & 3.97 \\
\hline Department of Land Settlement & DMU18 & 3.85 & 4.00 & 3.64 & 4.01 \\
\hline Ministry of Labor & DMU19 & 3.83 & 3.60 & 3.53 & 4.33 \\
\hline Department Census \& Statistics & DMU20 & 3.97 & 4.10 & 3.73 & 4.19 \\
\hline Ministry of Mahaweli \& Agriculture & DMU21 & 4.35 & 4.25 & 4.31 & 4.46 \\
\hline Department of Coast Conservation & DMU22 & 3.99 & 4.18 & 3.80 & 4.11 \\
\hline Foreign Ministry & DMU23 & 3.91 & 4.15 & 3.81 & 3.90 \\
\hline Department of Elections & DMU24 & 3.70 & 3.68 & 3.62 & 3.80 \\
\hline Department of Survey & DMU25 & 3.69 & 3.88 & 3.36 & 4.01 \\
\hline Department of Postal & DMU26 & 3.79 & 3.85 & 3.51 & 4.11 \\
\hline Department of Forest Conservation & DMU27 & 3.31 & 3.00 & 3.13 & 3.71 \\
\hline Department of Motor Traffic & DMU28 & 3.91 & 4.08 & 3.91 & 3.82 \\
\hline Department of Customs & DMU29 & 3.19 & 3.60 & 2.96 & 3.24 \\
\hline
\end{tabular}

\subsection{Methodology}

As mentioned in the abstract of this paper, a non-parametric data envelopment analysis (DEA) has been employed to measure the performance of ministries and the departments denoted as decision making units (DMUs). As per Coelli, a DMU's efficiency is depicted by the ratio of the sum of its weighted outputs to the sum of its weighted inputs [18]. DEA is applicable to the case of both public and private sector entities. DEA has widespread use across a whole host of areas of public or private service provision industries.

The data were analyzed using data envelopment analysis program DEAP Version 2.1 developed by Farrell [19]. DEAP enables us to construct a non-parametric frontier over the input and output data and calculate the efficiency scores. We used input-oriented constant return to the scale (CRS) and variable return to the scale (VRS) models to calculate technical efficiency and scale efficiency for 29 DMUs in our data. Using DEA, one can calculate each DMU's efficiency score, calculated in relation to an efficiency frontier. DMUs positioned on the efficiency frontier have an efficiency score of 
1. DMUs operating below the frontier have an efficiency score lesser than 1. DMUs can also be used for benchmarking, as DMUs that fall on efficient frontiers can serve as benchmark for the DMUs that fall below the frontier and, hence, peers at frontier can serve as guideposts for the slackers.

A non-parametric DEA can be conducted both from an input orientation as well as from an output orientation in order to ascertain technical efficiency (TE) scores. However, for this very situation that we are dealing with, input orientation will be most appropriate, as DMUs have control over only the inputs; public service DMUs are expected to provide a minimum level of service which is usually given, and cannot be arbitrarily controlled. Hence, input orientation has been taken while conducting the DEA. TE is explained as ability of the firm (or DMU in our case) to obtain maximum output from a given set of inputs, as proposed by Farrell [19]. Input-oriented TE describes the likelihood of reducing inputs to achieve the same level of output, while output-oriented TE describes the likelihood of increasing the outputs with the same level of input. Constant returns to scale technical efficiency (CRSTE) is a measure of inefficiency caused by misalignment in input and output configuration. Variable constant returns to scale technical efficiency scores (VRSTE) is a measure of inefficiency caused by managerial underperformance.

The approach for frontier estimation, originally suggested by Boles was later improved with mathematical programming methods by Afiat and Charnes et al. [20-22]. Later input oriented constant return to the scale and variable return to the scale forms of the model were proposed by Charnes, Cooper and Rhodes (hereinafter referred as CCR, and CRS/CCR for CCR model based on constant return to scale) [23]. Moreover, see Fare et al. for further elaboration on the same idea [24]. The CCR model defines the efficiency of a decision-making unit (DMU) as the maximum of a ratio of weighted outputs to weighted inputs, subject to the condition that the similar ratios for every DMU can be less than or equal to unity [20]. The CCR model can be presented with mathematical programming methods, as later suggested by both Afiat [21] and Charnes [22]. In order to attain a VRSTE measure, the authors have initiated from a CRS/CCR model in linear programming form and then introduced convexity constraint to adapt it for VRS; i.e., to maximize output (y) divided by input (x) subjected to weights vectors $\mathrm{u}^{\prime}$ for outputs and $\mathrm{v}^{\prime}$ for inputs [20]. Hence,

$$
\max _{u, v}\left(\frac{u^{\prime} y_{i}}{v^{\prime} x_{i}}\right)
$$

subject to

$$
\begin{gathered}
\left(\frac{u^{\prime} y_{j}}{v^{\prime} x_{j}}\right) \leq 1, j=1,2, \ldots, N \\
u, v \geq 0
\end{gathered}
$$

in order to avoid infinite solutions problem, we constrain this by

$$
\mathrm{v}^{\prime} \mathrm{x}_{\mathrm{i}}=1
$$

Hence, we get

$$
\max _{u, v}\left(\mu^{\prime} y_{i}\right)
$$

subject to

$$
\begin{gathered}
v^{\prime} \mathrm{x}_{i}=1, \\
\mu^{\prime} \mathrm{y}_{\mathrm{j}}-v^{\prime} \mathrm{x}_{\mathrm{j}} \leq 0, \mathrm{j}=1,2, \ldots, \mathrm{N}, \\
\mu, v \geq 0
\end{gathered}
$$


Here, $\mu$ and $v$, represent the transformation into the multiplier form of linear programming. At this point, the CCR model proposes to introduce duality in liner programming to derive the following envelopment form;

$$
\min _{\Theta, \lambda} \Theta
$$

subject to

$$
\begin{gathered}
-y_{i}+Y \lambda \geq 0, \\
\Theta x_{i}-X \lambda \geq 0, \\
\lambda \geq 0,
\end{gathered}
$$

Finally, here the convexity constraint $N 1^{\prime} \lambda=1$ is introduced to transform it to VRS as [9];

$$
\min _{\Theta \lambda} \Theta
$$

subject to

$$
\begin{gathered}
-\mathrm{y}_{\mathrm{i}}+\mathrm{Y} \lambda \geq 0, \\
\Theta \mathrm{x}_{i}-\mathrm{X} \lambda \geq 1 \\
\mathrm{N1}^{\prime} \lambda=1(\text { for VRS }) \\
\lambda \geq 1,
\end{gathered}
$$

Now this VRS model can work under the constraints as stipulated in the equations above and provide a reliable measure of efficiency. Here, Here, $\theta$ is a scalar and $\lambda$ is an $N \times 1$ vector of constants, $\mathrm{y}_{\mathrm{i}}$ is column vector of outputs, $\mathrm{Y}$ is output matrix defined as $m \times n, \mathrm{x}_{\mathrm{i}}$ is column vector of inputs, $\mathrm{X}$ is input matrix defined as $k \times n, \mathrm{~N}$ is the number of DMUs, $\mathrm{k}$ is number of inputs, $\mathrm{m}$ is number of outputs [20]. Efficiency score is equal to or less than 1 . The efficiency score equal to 1 means the DMU is on efficiency frontier line. The efficiency scores less than 1 mean that the DMU is inside of the efficiency frontier. Scale efficiency will be calculated as a ratio of CRSTE to VRSTE. Using DEAP 2.0 version, we are able to calculate not only efficiency per se, but peers, peer targets and slacks amongst our entities.

\section{Results}

Table 3 shows input-oriented efficiency summary for the 29 decision-making units (DMUs). The first column contains the DMUs under study. Column 7 shows the CRSTE, which is also denoted as total efficiency score. Column 8 shows pure technical efficiency measure named VRSTE; whereas column 9 indicates a scale efficiency measure (scale). Finally, column 10 shows increasing return to scale (IRS) decreasing (DRS), or constant (-) returns to scale for each DMU.

In the next sub-sections, important results gathered under the variable and constant returns to scale assumption with an input orientation have been explained. The results have been categorized into the following three sub-sections:

- Efficiency analysis

- Peer analysis

- Input/output targets analysis 
Table 3. Efficiency Results.

\begin{tabular}{|c|c|c|c|c|}
\hline \multirow{2}{*}{$\begin{array}{l}\text { Decision Making } \\
\text { Unit No. }\end{array}$} & \multicolumn{4}{|c|}{ Efficiency Results Summary } \\
\hline & $\begin{array}{l}\text { Constant Returns } \\
\text { to Scale (Col. 7) }\end{array}$ & $\begin{array}{l}\text { Variable Returns } \\
\text { to Scale (Col. 8) }\end{array}$ & Scale (Col. 9) & $\begin{array}{c}\text { Returns to } \\
\text { Scale (Col. 10) }\end{array}$ \\
\hline DMU1 & 0.988 & 0.989 & 0.999 & IRS \\
\hline DMU2 & 0.917 & 0.921 & 0.996 & IRS \\
\hline DMU3 & 0.944 & 0.945 & 1.000 & - \\
\hline DMU4 & 0.931 & 0.934 & 0.996 & IRS \\
\hline DMU5 & 0.953 & 0.955 & 0.998 & IRS \\
\hline DMU6 & 0.949 & 0.949 & 1.000 & - \\
\hline DMU7 & 0.930 & 0.930 & 1.000 & - \\
\hline DMU8 & 0.945 & 0.954 & 0.991 & IRS \\
\hline DMU9 & 0.953 & 0.954 & 1.000 & - \\
\hline DMU10 & 0.880 & 0.883 & 0.997 & IRS \\
\hline DMU11 & 0.911 & 0.984 & 0.925 & IRS \\
\hline DMU12 & 0.911 & 0.915 & 0.996 & IRS \\
\hline DMU13 & 0.979 & 0.979 & 1.000 & - \\
\hline DMU14 & 1.000 & 1.000 & 1.000 & - \\
\hline DMU15 & 0.948 & 0.974 & 0.973 & IRS \\
\hline DMU16 & 0.887 & 0.894 & 0.992 & IRS \\
\hline DMU17 & 0.910 & 0.910 & 1.000 & - \\
\hline DMU18 & 0.996 & 0.996 & 1.000 & - \\
\hline DMU19 & 0.887 & 0.887 & 1.000 & - \\
\hline DMU20 & 0.952 & 0.959 & 0.993 & DRS \\
\hline DMU21 & 0.961 & 1.000 & 0.961 & DRS \\
\hline DMU22 & 1.000 & 1.000 & 1.000 & - \\
\hline DMU23 & 0.993 & 0.994 & 0.999 & DRS \\
\hline DMU24 & 0.930 & 0.933 & 0.997 & IRS \\
\hline DMU25 & 0.922 & 0.926 & 0.995 & IRS \\
\hline DMU26 & 0.951 & 0.970 & 0.980 & DRS \\
\hline DMU27 & 1.000 & 1.000 & 1.000 & - \\
\hline DMU28 & 0.966 & 0.967 & 0.999 & DRS \\
\hline DMU29 & 1.000 & 1.000 & 1.000 & - \\
\hline Means & 0.950 & 0.960 & 0.990 & \\
\hline
\end{tabular}

\subsection{Efficiency Analysis}

On the whole, efficiency results (Table 3) show a 95\% mean score for VRSTE, meaning DMUs on the whole have a possibility to reduce their inputs by $5 \%$ and still maintain the same level of operations. With a $96 \%$ mean score for CRSTE, DMUs on the whole have a possibility to reduce their inputs by $4 \%$ and still maintain same level of operational efficiency. With a 99\% for scale efficiency, all DMUs can enhance efficiency by $1 \%$ by adjusting their operational scale. DMUs with IRS are having increasing returns to scale situation, indicating that efficiency can still be improved by operating at optimum operational levels. DMUs with DRS are in the state of decreasing returns to scale situation, indicating that efficiency can be improved by reverting to a decreased but optimum operating level. DMUs with a dash are facing CRS, meaning that they are operating at an optimal scale. The comparative efficiencies on both types of scale and their respective locales can be observed from Figure 1. 


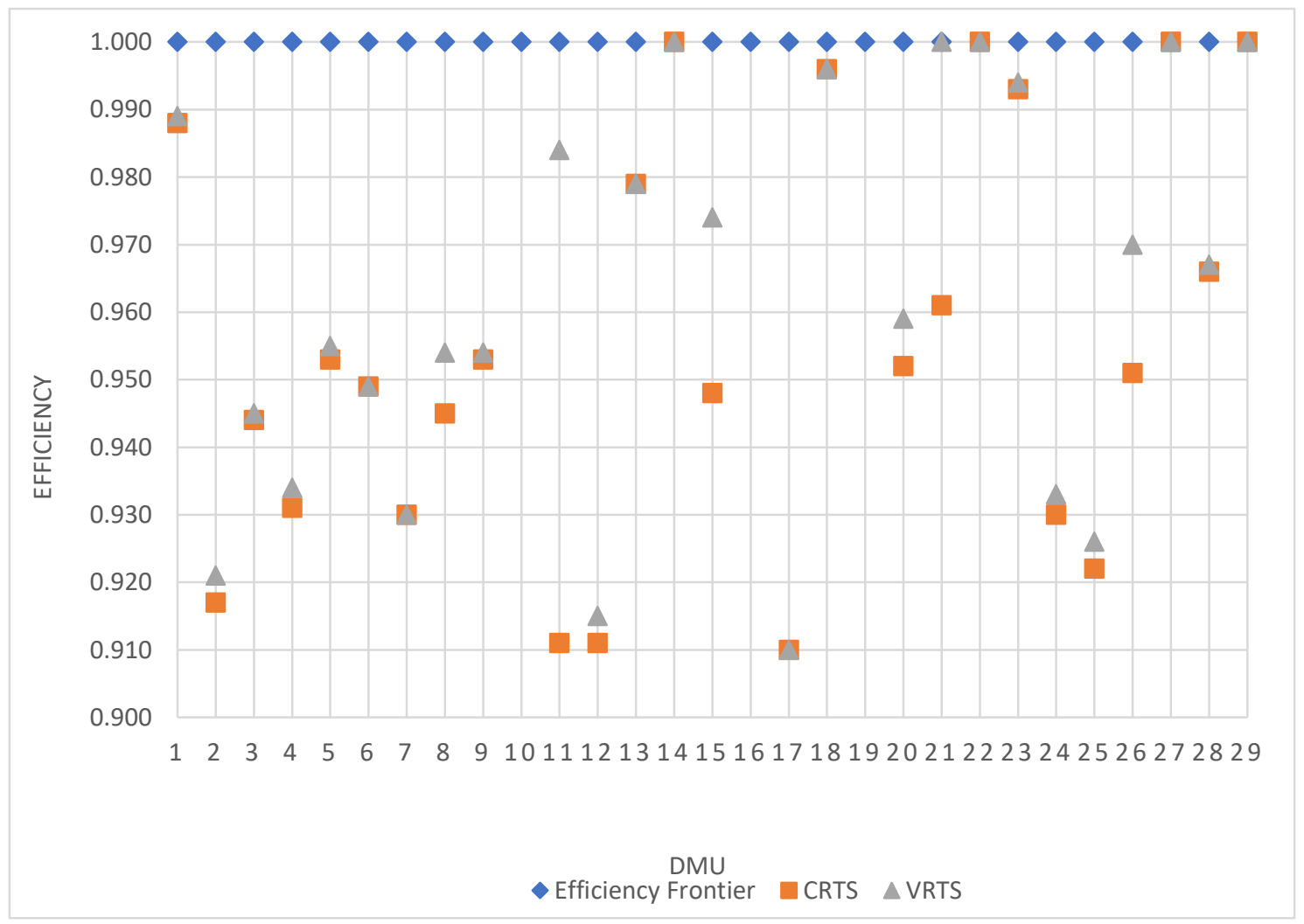

Figure 1. Efficiencies Chart.

\subsection{Peers Analysis}

Table 4 summarizes the peer position along with input and output target projections. The peer analysis shows that DMU14, DMU21, DMU22, DMU27 and DMU29 are peers to other DMUs in different iterations. These 5 DMUs also have a VRSTE of 1 each, meaning they have no other peer and thus have a 100\% VRS efficiency score. Furthermore, of these 5 DMUs, only DMU21 has not achieved $100 \%$ scale efficiency and is faced with a DRS; whereas all other 4 DMUs of this group have CRS, meaning they have no inefficiencies of scale. The VRS assumption is precisely represented in the envelopment form of the VRS model with a limitation of 1, i.e., $\Sigma \lambda=1$ (meaning sum of peer weights cannot exceed 1 or be less than 1). In short, DMU14, DMU22, DMU27 and DMU29 can serve as benchmark.

\subsection{Targets Analysis}

Targets analysis (Table 4) allows us a comparison between the actual performance levels achieved and the projected targets that should be achieved by various DMUs. Table 4 lays down the target inputs and output for all 29 DMUs. We should observe that only DMUs with consistent higher scores across various efficiency measures should be pursuing the target scores very closely. As an input-oriented approach has been taken, our focus should be on the input targets and to see how much each DMU is distant from or close to the indicated target for all 3 inputs. Moreover, one can establish cross-DMU performance assessment from this data. It is obvious that most DMUs are away from the targets generated by DEA. 
Table 4. Peers and Targets Analysis.

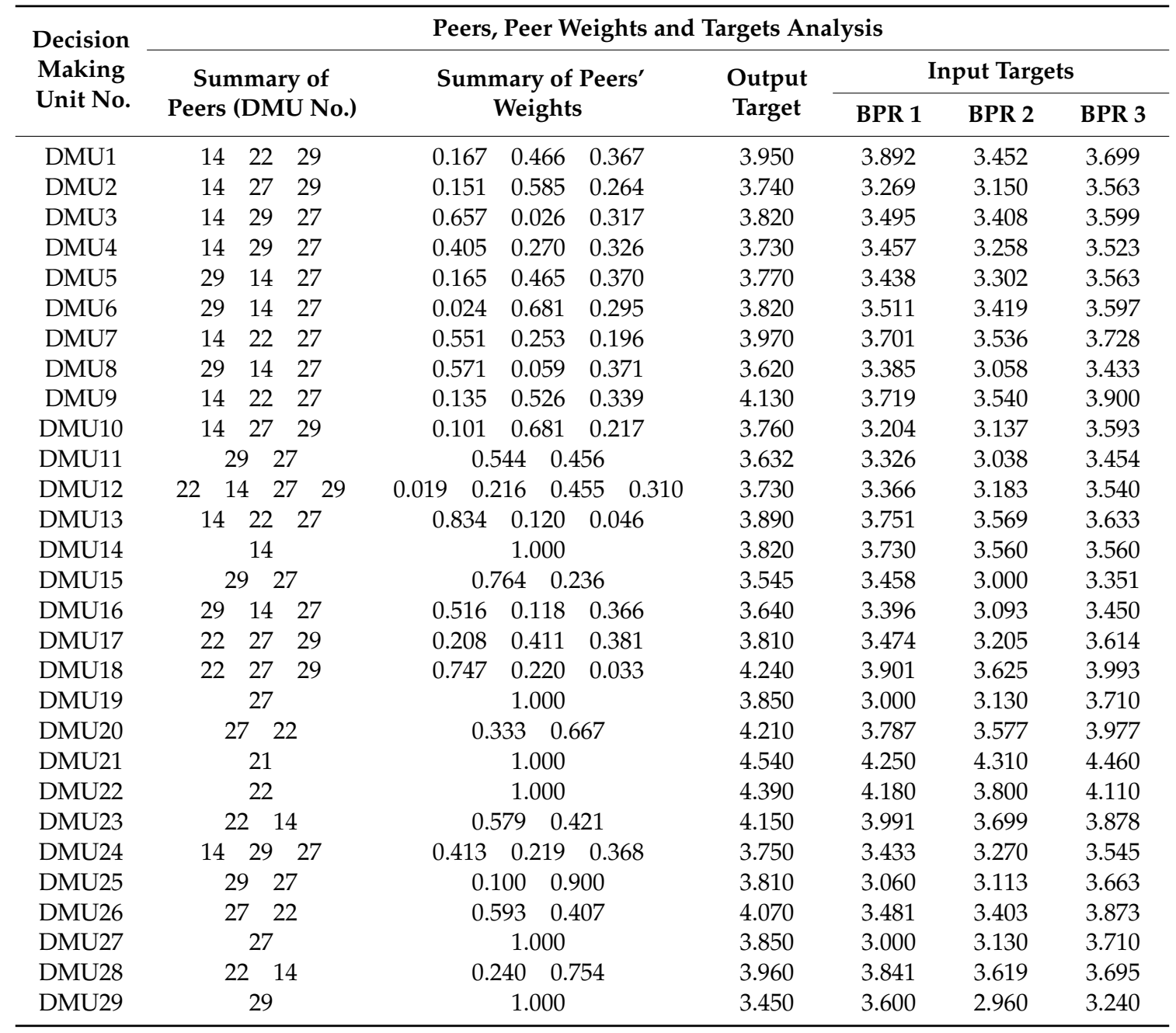

\section{Discussion}

Thanassoulis stated that Sri Lankan public administration structure has undergone at least three distinct public reform waves [17]. The first wave as explained in the report of Administrative Reforms Committee (ARC) laid down detailed/linked proposals with a major focus on civil service size. However, the first wave was only partially implemented as most reform measures were hampered by political instability. We have also already noted that Deshani et al. found that the second wave had a structural reform focus; however, the target areas were not clear and implementation of the reforms resulted in disarray and did not result in any noticeable performance improvement [9]. The third and the most recent wave introduced a major strategic shift in the philosophy and the structure of the public service administration.

Despite many studies related to the public service reforms in Sri Lanka, none have yet assessed the impact of the third and the most recent wave of reforms in the form of BPR regime. From our findings in the literature section, we already know that Deshani et al. performed a cursory study of the three waves and his findings were mostly related to employment reforms [9]. As compared to the 3rd wave, the 1st and the 2nd waves have been mostly economy-related reforms. Deshani et al studied the effectiveness of public service delivery in Galle district of Sri Lanka only, and that too from the perspective of public entrepreneurship [10]. Sultonov used DEA approach to estimate health expenditure efficiency for developing countries including Sri Lanka [25]. In this study, life expectancy at birth and infant survival are used as output, and per capita total expenditure on health, physicians' density, nursing density and hospital beds are used as input. The results show that, in general, efficiency scores for Sri Lanka are 
only slightly higher than the average of the efficiency scores for developing countries, but the efficiency scores do not reach the efficiency frontier line for developing countries.

We carried out this study from the perspective of a totality of public service provision in Sri Lanka in the wake of most recent BPR regime. We cannot take an entrepreneurial perspective, as expected output is given (i.e., public satisfaction per se) and only change can be implemented from the inputs, i.e., the reformative actions. We identified three reformative actions forming the core of the BPR regime namely, rules, structure, and the control actions. Through changes in these three input areas, we assessed the efficiency of the public service systems in Sri Lanka. As a logical consequence, we applied input-oriented DEA to the survey data in order to identify the overall as well as the relative efficiency of the service providers. Accordingly, the questionnaire was structured in a format to allow us determine the efficiency status of the PSD. The data analysis shows that 4 DMUs out of a total of 29 DMUs are efficient with reference to the scale; whereas DMU21, though not at 100\% scale efficiency, still falls in the peer groups (Table 4). The disparity of the scale efficiencies can be attributed to the latent inefficiencies or lack of full implementation of the BPR regime across the DMU. Out of 29 D\&Ms, 12 are having IRS, meaning there is still room to improve performance in order to achieve full-scale efficiency. Five DMUs are faced with DRS, meaning there is a capacity to increase the scale of service delivery in order to achieve scale efficiency. Other 12 DMUs are in a state of CRS, including 4 DMUs (DMU14, DMU22, DMU27 and DMU29) who have achieved CRSTE, VRSTE as well as scale efficiency. It has been demonstrated by Rodder et al. and Annrong et al. that adjusting the scale towards optimum scale we can enhance the level of efficiency [26,27]. We can therefore safely conclude that, out of 29 DMUs, 25 DMUs can increase public service delivery efficiency by adjusting the scale of their operations.

Peer analysis has given us an insight into the rankings of the DMUs and we can identify the benchmark DMUs from the lagging DMUs (Table 4. Understanding and making use of peer weights is not very straightforward; however, the same results can be adjusted to understand and explain cross efficiency by adopting gap-minimization techniques. Gap minimization will help eliminate extreme efficiency cases through an efficiency landscape developed by applying aggressive and benevolent cross efficiency evaluation approach. This approach has been fairly explained [28], and can be applied in situations of extreme efficiency. However, in our case, most efficient as well as less efficient DMUs are located fairly close by, and none can be identified as extreme efficiency cases.

Finally, our analysis in Table 4 has also produced targets for both input as well as output. Najmeh et al. explained in their model that target setting could be integrated with performance assessment while simultaneously taking decision makers' preferences into account [29]. However, they applied an output-oriented approach into their model. On the other hand, we are using an input-oriented model, so we shall mostly focus on an input reduction approach to enhance efficiency of our lagging DMUs. The authors further proposed an input-oriented target setting approach for DEA, and we are inclined to favor their approach in this matter. Findings of two earlier studies by Jehan et al. also supplement the concepts developed in this paper $[30,31]$.

\section{Conclusions}

In this paper, the authors have conducted an in-depth analysis open innovation-based BPR regime installed in the PSD sector of Sri Lanka since 2010. The authors have reasonably positioned the study in a comparative light and in the process emphasized the originality of their data and outcomes by providing and comparing empirical evidence. The study found that the results of the BPR implementation have been mixed across the 29 D\&Ms surveyed in the study. It was found that while efficiency has been fairly high in some D\&Ms, many others were lagging behind and efficiencies for such D\&Ms can be improved. Our results show that most DMUs are off the input target levels. By applying appropriate peer weights, we can steer our DMUs towards the optimal performance level and cross DMU efficiency comparison can be highlighted even further. The benchmarking approach displayed in the paper can help slackers to improve their performance and achieve optimal efficiency and scale levels. The results thus obtained should form the basis for an IOI feedback to allow a 
continuous process innovation and reform in the PSD of the country. However, as in this paper we are offering an analysis of the performance as such, and we are not proposing to offer optimal performance strategy, so we shall leave that for a future study. While the data are from one country, the results and the analytical approach applied in this paper can be replicated to assess the open innovation based BPR regimes anywhere else too.

Author Contributions: Conceptualization, V.W.E. and S.N.J.; methodology, V.W.E. and S.N.J.; formal analysis, V.W.E. and S.N.J.; Resources, V.W.E.; data curating, V.W.E.; writing—original draft preparation, V.W.E. and S.N.J.; writing—review and editing, V.W.E. and S.N.J.; visualization, V.W.E. and S.N.J.; supervision, S.N.J. All authors have read and agreed to the published version of the manuscript.

Funding: This research received no external funding.

Acknowledgments: Authors are deeply thankful to functionaries of various departments and ministries of the government of Sri Lanka who assisted in dissemination and collection of the questionnaire.

Conflicts of Interest: The authors declare no conflict of interest.

\section{References}

1. Meyer, E. The Specificity of Sri Lanka: Towards a Comparative History of Sri Lanka and India. Econ. Political Wkly. 1996, 31, 395-398. Available online: www.jstor.org/stable/4403796 (accessed on 5 October 2020).

2. Hsieh, C. What Explains the Industrial Revolution in East Asia? Evidence from the Factor Markets. Am. Econ. Rev. 2002, 92, 502-526. [CrossRef]

3. Hammer, M.; Champy, J. Reengineering the corporation: A manifesto for business revolution. Bus. Horiz. 1993, 36, 90-91. [CrossRef]

4. Ezigbo, C.A. Advanced Management Theory and Applications; Immaculate Publication Ltd.: Enugu, Nigeria, 2011; pp. 83-90.

5. Gassmann, O.; Ellen, E. Towards a Theory of Open Innovation: Three Core Process Archetypes. In Proceedings of the R\&D Management Conference (RADMA) 2004, Lisbon, Portugal, 7-9 July 2004; pp. 6-7.

6. Information and Communication Technology Agency of Sri Lanka. Detailed Study of the Lanka eGovernment Strategy Project, ICTA/AFC/IC/IC03/58. Available online: https://www.gov.lk/elaws/wordpress/wp-content/ uploads/2015/08/GOSL-Integrated-eGovernment-Strategy-Final-Submitted-17-Aug-2014-vcio-1.pdf (accessed on 6 October 2020).

7. Park, D.; Noland, M. Developing the Service Sector as an Engine of Growth for Asia; Asian Development Bank: Mandaluyong City, Philippines, 2013.

8. McCourt, W. Finding a way forward on public employment reform: A Sri Lankan case study. Asia Pac. J. Hum. Resour. 2001, 39, 1-22. [CrossRef]

9. Deshani, A.L.; Weerasinghe, R.N. Public Entrepreneurship and Delivering Public Services Effectively: A Study in Public Organizations in Galle District. In Proceedings of the 12th International Conference on Business Management, Nugegoda, Sri Lanka, 7 December 2015.

10. Ghatari, A.; Shamsi, Z.; Vedadi, A. Business Process Reengineering in Public Sector: Ranking the Implementation Barriers. Int. J. Process Manag. Benchmarking 2014, 4, 1-18. [CrossRef]

11. Ozcelik, Y. Do business process reengineering projects payoff? Evidence from the United States. Int. J. Project Manag. 2010, 28, 7-13. [CrossRef]

12. Hesson, M.; Ameed, H.; Samaka, M. Business process reengineering in UAE public sector: A town planning case study. Bus. Process Manag. J. 2007, 13, 348-378. [CrossRef]

13. Thong, J.Y.; Yap, C.S.; Seah, K.L. Business Process Reengineering in the Public Sector: The Case of the Housing Development Board in Singapore. J. Manag. Inf. Syst. 2000, 17, 245-270. [CrossRef]

14. Chesbrough, H.W. Business model innovation: Opportunities and barriers. Long Range Plan. 2010, 43, 354-363. [CrossRef]

15. Fernando, R.L.S. Managerial Innovation in Service Delivery in Public Sector Organizations in Sri Lanka, Governance and Development; Shrabon Printing Press: Dhaka, Bangladesh, 2006; pp. 221-237.

16. Wijesinghe, D. Administrative Reforms: International Perspectives and the Case of Sri Lanka; Government of Sri Lanka: Colombo, Sri Lanka, 1997. 
17. Thanassoulis, E.; Portela, M.C.S.; Despić, O. Data Envelopment Analysis: The Mathematical Programming Approach to Efficiency Analysis. In The Measurement of Productive Efficiency and Productivity Change; Oxford University Press: Oxford, UK, 2008.

18. Coelli, T.J. A Guide to DEAP Version 2.1: A Data Envelopment Analysis (Computer) Program; CEPA Working Papers No.8/96; University of New England: New South Wales, Australia, 1996.

19. Farrell, M. The Measurement of Productive Efficiency. J. R. Stat. Soc. Ser. A (Gen.) 1957, 120, $253-290$. [CrossRef]

20. Boles, J.N. Efficiency squared-efficient computation of efficiency indexes. In Proceedings of the Annual Meeting; Western Farm Economics Association, Long Beach, CA, USA, 15-17 August 1966; pp. 137-142.

21. Afriat, S. Efficiency Estimation of Production Functions. Int. Econ. Rev. 1972, 13, 568-598. [CrossRef]

22. Charnes, A.; William, W.C.; Edwardo, R. Measuring the efficiency of decision making units. Eur. J. Oper. Res. 1978, 2, 429-444. Available online: https://farapaper.com/wp-content/uploads/2019/06/FardapaperMeasuring-the-efficiency-of-decision-making-units.pdf (accessed on 14 October 2020). [CrossRef]

23. Banker, R.D.; Charnes, A.; Cooper, W.W. Some Models for Estimating Technical and Scale Inefficiencies in Data Envelopment Analysis. Manag. Sci. 1984, 30, 1078-1092. Available online: http://www.jstor.org/stable/ 2631725 (accessed on 1 October 2020). [CrossRef]

24. Fare, R.; Grosskopf, S. Nonparametric tests of regularity, Farrell efficiency, and goodness-of-fit. J. Economy. 2005, 6, 415-425. [CrossRef]

25. Sultonov, M. Health expenditure efficiency in the Commonwealth of Independent States: A data envelopment analysis approach. Transit. Stud. Rev. 2011, 18, 384-404.

26. Rödder, W.; Kleine, A.; Dellnitz, A. Scaling production and improving efficiency in DEA: An interactive approach. J. Ind. Eng. Int. 2018, 14, 501-510. [CrossRef]

27. Yang, A.; Zhang, Z.; Zhang, Y.; Chen, D. Gap minimization for peer-evaluation in DEA cross-efficiency. J. Appl. Math. 2014, 1-7. Available online: https://www.hindawi.com/journals/jam/2014/453749/ (accessed on 14 October 2020).

28. Jian-Bo, Y.; Brandon, Y.H.; Wong, D.; Theodor, J.S. Integrating DEA-oriented performance assessment and target setting using interactive MOLP methods. Eur. J. Oper. Res. 2009, 195, 205-222.

29. Najmeh, M.; Farhad, H.L.; Azmi, B.J. Target setting in data envelopment analysis using MOLP. Appl. Math. Modeling 2011, 35, 328-338.

30. Jehan, S.N.; Nishantha, G.G.D.; Jehan, S.Q. E-governance initiative in Sri Lankan public service delivery. In Proceedings of the 12th International Conference on Advanced Communication Technology (ICACT), Gangwon-Do, Korea, 7-10 February 2010; pp. 1625-1629.

31. Jehan, S.N.; Nishantha, G.G.D.; Uchida, Y. BPR in large public organizations: A case of managing change in a developing country. J. Jpn. Assoc. Manag. Syst. 2010, 27, 25-31.

Publisher's Note: MDPI stays neutral with regard to jurisdictional claims in published maps and institutional affiliations.

(C) 2020 by the authors. Licensee MDPI, Basel, Switzerland. This article is an open access article distributed under the terms and conditions of the Creative Commons Attribution (CC BY) license (http://creativecommons.org/licenses/by/4.0/). 